\title{
Ultrastructural Evaluation of the Hybrid Layer After Cementation of Fiber Posts Using Adhesive Systems with Different Curing Modes
}

\author{
Luciana Rigueira ABOU-ID \\ Luís Fernando S.A. MORGAN \\ Gerluza Aparecida Borges SILVA \\ Luiz Thadeu de Abreu POLETTO \\ Lincoln Dias LANZA \\ Rodrigo de Castro ALBUQUERQUE \\ Department of Restorative Dentistry, Dental School, \\ UFMG - Federal University of Minas Gerais, Belo Horizonte, MG, Brazil
}

\begin{abstract}
This in vitro study evaluated the adhesive interface of intraradicular fiber glass posts and root dentin using scanning electron microscopy (SEM). Forty-eight single-rooted premolars were randomly divided into 6 groups consisting of chemical, dual, or light cured adhesive systems combined with either chemical or dual cure resin cements. Scanning electron microscopic analysis showed the best results for continuity, density and morphology of the hybrid layer and resin tags for the combination of a self-cure adhesive with self-cure cement resin, followed by a dual-cure adhesive with self-cure cement resin, and finally a light-cure adhesive with self-cure cement. For the dual-cure resin cement, the same relation may be observed. The apical third was the most critical region for evaluated the criteria for all combinations of materials (Kruskal-Wallis and Friedman tests; $p<0.001$ ). Generally, the simplification of steps in the adhesive system and the polymerization reaction of resin adhesives and cements produced a direct effect on the quality of the adhesive post/dentin substrate interface.
\end{abstract}

Key Words: Fiber posts, bonding techniques, scanning electron microscopy.

\section{INTRODUCTION}

Metallic cores or prefabricated posts are often needed as an auxiliary method of retention for the filling or reconstruction of endodontically treated teeth. Since their introduction by Duret et al. in the 1990's (1), the use of fiberglass posts has increased rapidly due to their advantages (2) when used as recommended.

An adhesive technique with resin cement is recommended for this type of post. However, this operative step can be complex due to various factors, such as the heterogeneity of the dental root substrate (3); instrument access at increased depths (4); adjustment of the post (5); adhesive systems; and resin cements from different presentations, application techniques, and reaction types (6-13). Due to these various aspects, the performance and interaction among these materials need to be better understood.

The objective of this study was to evaluate the resin cement/dentin interface for combinations of adhesive systems and resin cements with different types of curing modes. The null hypothesis is that all combinations of adhesive systems and resin cements present similar results, regardless of the type of polymerization.

\section{MATERIAL AND METHODS}

Forty-eight sound single-rooted premolars extracted due to orthodontic reasons were selected for this study and stored in $10 \%$ formalin. Approval was received from the Ethics Committee of the Federal University of Minas Gerais - UFMG (ETIC 310/04).

After endodontic treatment, the crowns of the 
teeth were removed with an Isomet 1000 cutter (Buehler, Lake Bluff, IL, USA), standardizing the root length to $14 \mathrm{~mm}$. The root canal was opened with $\# 2,3,4$ and 5 (Maillefer, Tulsa, OK, USA) to obtain a $9.0 \mathrm{~mm}$ long canal space.

Canal walls were etched with $37 \%$ phosphoric acid (Super Etch; SDI, Victoria, Australia) using a syringe for $15 \mathrm{~s}$, followed by washing for $30 \mathrm{~s}$. Excess water was removed by light air-drying and absorbent paper points. The smooth fiber glass posts, $1.5 \mathrm{~mm}$ in diameter (Angelus, Londrina, PR, Brazil), specially made for this study, were treated with $37 \%$ phosphoric acid for $1 \mathrm{~min}$, rinsed, and silanized (Monobond $\mathrm{S}$; Ivoclar Vivadent, Schaan, Liechtenstein). Next, the adhesive system was applied. The interactions between the adhesive systems and resin cements of different types of chemical reaction were analyzed according to the following groups:

G1: self-cure adhesive Lok (SDI) + self cure Post-Cement Hi-X (Bisco Inc., Schaumburg, IL, USA). The lok (SDI) primer was applied to the root dentin using an ultrathin microbrush. Next, the Lok base and catalyst mixture was applied. After having applied the mixed base and catalyst pastes, the resin cement was introduced into the root canal with a Centrix injector. The post was then introduced, and the excess cement was removed with a brush.

G2: dual-cure adhesive Excite DSC small/endo (Ivoclar Vivadent) + self cure Post-Cement Hi-X (Bisco Inc.). The adhesive was applied and light cured for $20 \mathrm{~s}$ (Optilight; Gnatus, Ribeirão Preto, SP, Brazil). Cement was applied using the same protocol used in G1.

G3: light-cure adhesive One Step (Bisco Inc.) + self cure Post-Cement Hi-X (Bisco). The adhesive was applied and light cured for $20 \mathrm{~s}$. The application of resin cement followed the same procedure as in G1.

G4: self cure adhesive Lok (SDI) + dual cure resin cement Variolink II (Ivoclar Vivadent). The adhesive was applied in the same manner as in G1. The dual-cure resin cement was mixed and inserted into the root canal with a Centrix injector. The excess was removed with a microbrush and light cured for $40 \mathrm{~s}$.

G5: dual-cure adhesive Excite DSC (Ivoclar Vivadent) + dual-cure resin cement Variolink II (Ivoclar Vivadent). The application and curing of the adhesive system was carried out in the same manner as in G2. Mixing, insertion and polymerization of the cement followed the same procedure as in G4.

G6: light-cure adhesive One Step (Bisco) + dual- cure resin cement Variolink II (Ivoclar Vivadent). The adhesive and resin cement were mixed, inserted, and photoactivated in the same manner as in G3 and G5, respectively. Light curing of the adhesive or cement was necessary in this group.

Then, except for G1, in which self cure materials were used, the root surfaces were covered with aluminum foil to prevent the introduction of any external light that was not intentionally introduced through the upper end of the post in an axial direction.

All specimens were stored for 7 days and then the roots were bisected longitudinally. The resulting 96 root halves was processed according to the each type of analysis: hybrid layer or resin tags. The specimens were subjected critical point drying (14) and examined with a scanning electron microscope (JSM 840A; Jeol, Tokyo, Japan).

For analysis of the adhesive interface by continuity of the hybrid layer, 48 root halves were treated with $37 \%$ phosphoric acid, rinsed and deproteinized with sodium hypochlorite at $2.5 \%$ for $2 \mathrm{~min}$. The specimens were fixed on aluminum stubs and sputter-coated (Edwards Pirani 501; Scancoat Six, UK) for $2 \mathrm{~min}$. SEM analysis was performed at magnifications of $\times 400$ and $\times 1500$, in three bands of observation: cervical third (1st, 2nd and 3rd mm); middle third (4th, 5th and 6th $\mathrm{mm}$ ); and apical third (7th, 8th and 9th $\mathrm{mm}$ ), using the cervical border as a reference. A descriptive measure of 0 to 3 was used to evaluate the continuity of the hybrid layer. Thus, " 0 " represented the continuity of the hybrid layer in all thirds of the root, i.e., an absence of fissures in all thirds; "1" represented a continuity in two thirds; "2" represented a continuity in at least one third; and " 3 " indicated that all thirds presented a discontinuity in the hybrid layer or fissures.

The non-parametric Kruskal-Wallis test $(\alpha=0.05)$ was used for the statistical analysis of the 3 levels studied and comparison among the 6 treatment groups as regards the presence of gaps between post and cement (GPC), gaps within the cement layer (GC), gaps between the adhesive layer and cement (GCA), gaps within the adhesive layer (GA), and gaps between the adhesive layer and dentine (GAD) for the continuity of the hybrid layer in thirds.

For analysis of resin tags, the remaining 48 root halves were completely demineralized with $37 \%$ hydrochloric acid for $48 \mathrm{~h}$ and $2 \%$ sodium hypochlorite for $10 \mathrm{~min}$, dissolving the dental substrate completely, in order to permit visualization of the resin, extensions 
and adhesive side branches. The specimens were stored, fixed, sputter-coated and evaluated as described for the hybrid layer analysis. A magnification of $\times 2500$ was employed. The density and morphology of resin tags were ranked with scores from " 0 " to " 4 " where: "0" represented the absence of tags, "1" few tags from 2 to $7 \mu \mathrm{m}$, " 2 " few tags from 7.1 to $15 \mu \mathrm{m}$, " 3 " many tags greater than $15 \mu \mathrm{m}$, and " 4 " many tags of more than 15 $\mu \mathrm{m}$ and with side branches.

Comparisons among the 3 levels, in terms of density score and morphology of resin tags by group, were analyzed statistically by the Friedman test $(p<0.05)$.

\section{RESULTS}

\section{Analysis of the Adhesive Interface by Continuity of Hybrid Layer}

Statistical analysis of the 6 groups in relation to the examined thirds showed significant differences. The cervical third presented the smallest number of gaps, followed by the middle and apical thirds, respectively (Table 1).

Type GA gaps were the most common, followed by GAD, GCA and GPC. The adhesive Lok showed fewer GPC gaps, followed by Excite DSC and One Step, mainly in the apical third (Fig. 1). As regards the cements used, Hi-X showed no GPC gaps, whereas Variolink II showed GPC gaps in the middle third and even more strikingly in the apical third.
In relation to the continuity of the hybrid layer, groups using self cure adhesives, G1 and G4, presented the best results among the three root thirds. Groups using dual cure adhesives (G2 and G5) presented intermediate results, while groups using light cure adhesives (G3 and G6) presented the worst results (Table 1).

\section{Analysis of Resin Tags}

Comparative analysis among the groups regarding the scores of the density and morphology of resin tags per groups and thirds revealed that the apical third was

Table 1. Comparative analysis of the 6 experimental groups regarding the number of gaps and the continuity of the hybrid layer in the three root canal thirds. Descriptive measure scores of 0 to 3.

\begin{tabular}{llllll}
\hline \multirow{2}{*}{ Groups } & \multicolumn{2}{c}{$\begin{array}{c}\text { Number } \\
\text { of gaps }\end{array}$} & & \multicolumn{2}{c}{$\begin{array}{c}\text { Continuity of } \\
\text { hybrid layer }\end{array}$} \\
\cline { 2 - 3 } \cline { 5 - 6 } \cline { 5 - 6 } G1 & Mean & S.D. & & Mean & S.D. \\
\hline G2 & $0.25 \mathrm{~A}$ & 0.5 & & $2.7 \mathrm{~A}$ & 0.5 \\
G3 & $1.0 \mathrm{~B}$ & 0.5 & & $2.0 \mathrm{~B}$ & 0.5 \\
G4 & $2.0 \mathrm{~B}$ & 1.1 & & $1.0 \mathrm{C}$ & 1.1 \\
G5 & $0.6 \mathrm{~A}$ & 0.9 & & $2.7 \mathrm{~A}$ & 0.5 \\
G6 & $1.7 \mathrm{~B}$ & 0.7 & & $1.9 \mathrm{~B}$ & 1.1 \\
\hline
\end{tabular}

Different letters indicate statistically significant difference among the groups (Kruskal-Wallis test $\mathrm{p}<0.05$ ). S.D.: standard deviations.
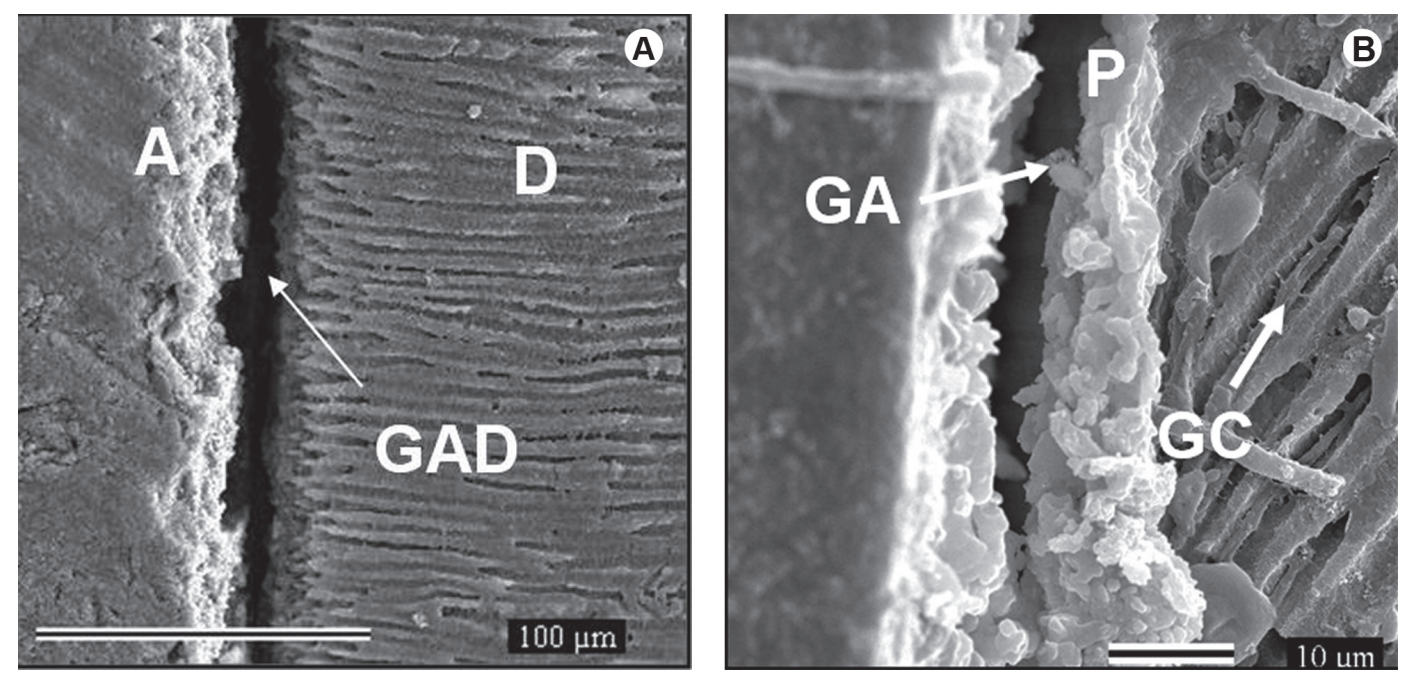

Figure 1. Presence of gaps in the hybrid layer in the middle third in G3 (A) (Original magnification $\times 500$ ) and in the apical third in G6 (B) (Original magnification $\times 1500$ ). A: adhesive; D: dentin; GAD: gaps between the adhesive layer and dentin; GA: gaps within the adhesive layer; GC: gaps within the cement layer; P: post area. 

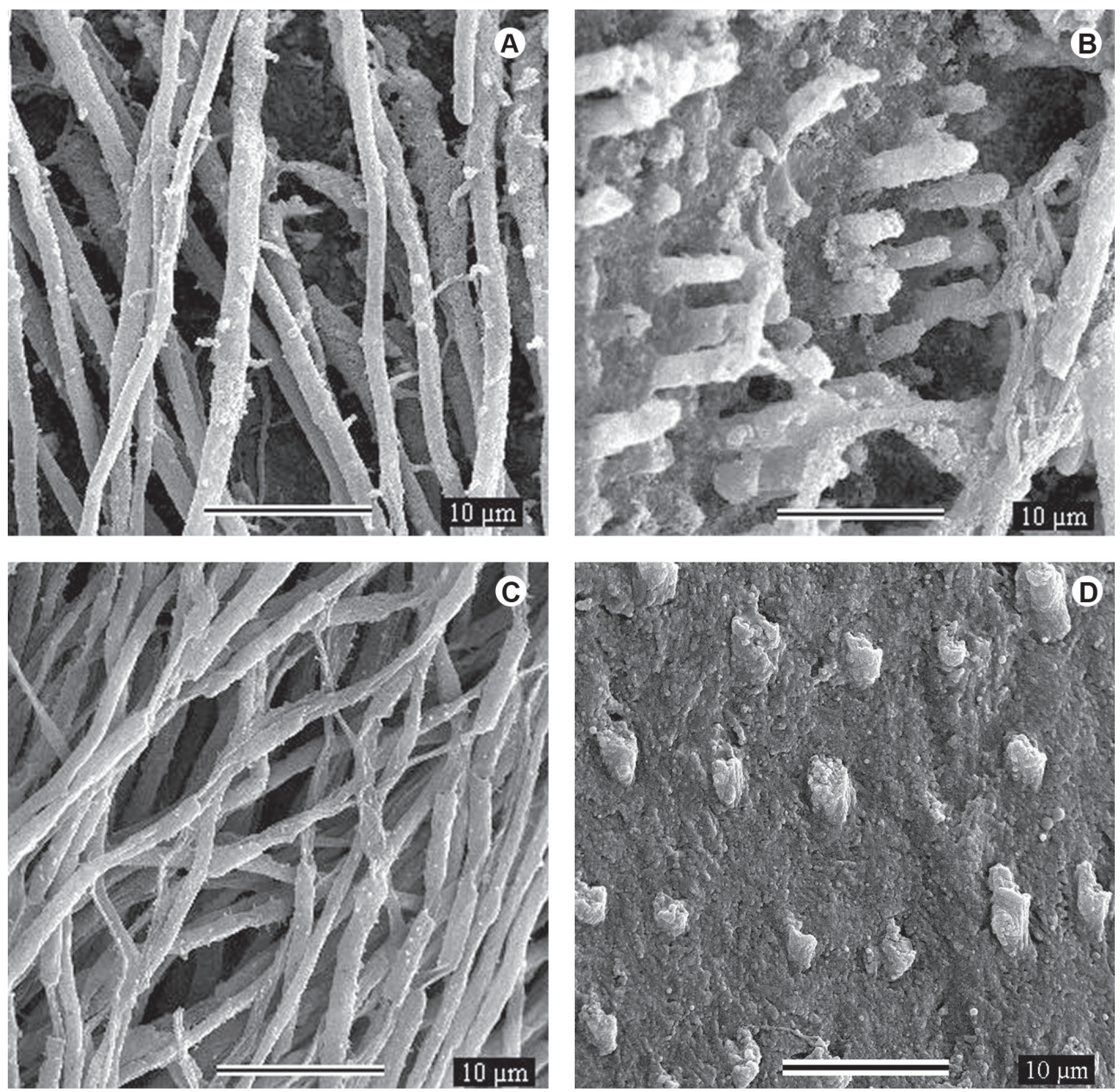

Figure 2. Density and morphology of resin tags in the middle root third. A: G1, score 4; B: G2, score 2; C: G4, score 3; D: G5, score 1 (Original magnification $\times 2500)$.

Table 2. Comparative analysis among the experimental groups regarding the scores of the density and morphology of resin tags per groups and thirds. Scores from 0 to 4 .

\begin{tabular}{|c|c|c|c|c|c|c|c|c|}
\hline \multirow{2}{*}{ Group } & \multicolumn{2}{|c|}{ Cervical third } & \multicolumn{2}{|c|}{ Middle third } & \multicolumn{2}{|c|}{ Apical third } & \multicolumn{2}{|c|}{ Mean of thirds } \\
\hline & Mean & S.D. & Mean & S.D. & Mean & S.D. & Mean & S.D. \\
\hline G1 & $3.6 \mathrm{Aa}$ & 0.5 & $3.5 \mathrm{Aa}$ & 0.5 & $2.5 \mathrm{Ab}$ & 0.5 & $3.2 \mathrm{~A}$ & 0.5 \\
\hline G2 & $3.5 \mathrm{Aa}$ & 0.5 & $2.6 \mathrm{Ba}$ & 0.5 & $0.7 \mathrm{Bb}$ & 1.0 & $2.3 \mathrm{~B}$ & 0.4 \\
\hline G3 & $2.7 \mathrm{Ba}$ & 0.7 & $1.0 \mathrm{Cb}$ & 1.1 & $0.4 \mathrm{Cb}$ & 0.5 & $1.4 \mathrm{C}$ & 0.7 \\
\hline G4 & $3.5 \mathrm{Aa}$ & 0.5 & $2.5 \mathrm{Bb}$ & 0.5 & $2.1 \mathrm{Ab}$ & 0.4 & $2.7 \mathrm{~A}$ & 0.4 \\
\hline G5 & $3.5 \mathrm{Aa}$ & 0.5 & $2.5 \mathrm{Bb}$ & 0.5 & $0.7 \mathrm{Bc}$ & 0.9 & $2.2 \mathrm{~B}$ & 0.6 \\
\hline G6 & $3.1 \mathrm{Ba}$ & 0.4 & $1.1 \mathrm{Cb}$ & 1.0 & $0.2 \mathrm{Cc}$ & 0.5 & $1.5 \mathrm{C}$ & 0.4 \\
\hline
\end{tabular}

Uppercase letters compare values per column (thirds) ( $\mathrm{p}<0.001$; Kruskal-Wallis test) and lowercase letters compare values per rows (groups) $(\mathrm{p}<0.001$; Friedman test). Mean of thirds: cervical third + middle third + apical third/3. Different notations indicate statistically significant differences. S.D.: standard deviations. 
the most critical region for all groups (Table 2). In the cervical third, G1, G2, G4, and G5 showed the best results, while G3 and G6 had the worst. In the middle third, G1 presented the best results, followed by G2, G4, and G5 (Fig. 2), with intermediate results, and G3 and G6 with the worst results. In the apical third, the groups with the best results were G1 and G4. The worst result was obtained in G3. The highest mean scores among all root thirds was obtained in G1 and G4, while the lowest mean score was obtained in G6.

\section{DISCUSSION}

The results of the present study suggest that the density and morphology of the hybrid layer is directly related to the type of polymerization of adhesive materials and to the root depth, thus rejecting the null hypothesis.

The best performance in all thirds, with respect to the continuity of the hybrid layer and the resin tags, was observed for the self-cure adhesive and resin cement, followed by the dual cure and light cure systems, respectively. The hypothesis that seems to explain these results is related to the luminous intensity in the deepest regions of the post space, the morphology of the root substrate, the stress generated by the cavity configuration (C-factor), and the interaction between adhesive and resin cement systems.

The reduction of luminosity due to the distance of the light source from the apical third, results in incomplete polymerization of resin materials, whose chemical reaction is dependent on light energy, especially at greater depths $(15,16)$. The relevance of this fact was demonstrated by Kanehira et al. (17), who found a directly proportional relationship between the degree of adhesive conversion and bond strength, and Giachetti et al. (18), who showed the importance of light in the polymerization of light cure or dual cure adhesives.

Another aspect to be analyzed is the heterogeneous morphology of root dentin. According to Ferrari et al. (19), a reduction of tubular density can be observed in the deeper regions of root dentin. This seems to justify, in part, the results obtained in the comparisons among the three thirds within the post space, regardless of the group evaluated. In this manner, the apical third of the post space was the most critical in producing continuous hybrid layers and producing resin tags, as reported elsewhere (20). Difficulty of access of adhesive applicators to the deepest regions may also influence the quality of the adhesive interface. The brushes used in this experiment were of the ultra-fine type for G1, G3, G4, and G6. In G2 and G5, the small/endo that comes with the Excite DSC kit was used its own applicator. The performance of the ultra-fine type of brush present better results in the study by Vichi et al. (20), and for this reason does not appear to have influenced the results.

The intraradicular region has a comparatively unfavorable cavity configuration. According to Bouillaguet et al. (21), the C-factor is considerably greater than in intracoronal restorations. Therefore, it is acceptable that dual cure resin cements and adhesives or light cure resins develop higher tension at the adhesive interface. As a result of this tension caused by polymerization, gaps may form in the two adhesive interfaces: the post/adhesive and the adhesive/root interfaces. These gaps were mainly found in G6, which combined light cure adhesive and resin cement.

The incompatibility between adhesive and resin cement systems should be considered in the analysis of the types of gaps found in the present study. When the chemical characteristics of the adhesive system are antagonistic, cement gaps can be observed $(22,23)$. In this study, in G5 and G6, the GCA-type gaps occurred in a larger number for the combination of dual cement with simplified, two-step adhesives. Thus, the classic, threestep adhesives do not present a risk of incompatibility. This is because the acid monomers that are contained in the first step and the final application of the adhesive prevent these monomers from coming into contact with the cement.

Generally, the simplification of steps in the adhesive system and the polymerization reaction of adhesives and resin cements have a direct effect on the adhesive post/dentin substrate interface. When a lightcure component was added to the experimental cementing protocol, inferior results were always observed. When light cure components were incorporated either in the adhesive or the cement the results worsened.

Clinically, it appears to be more reliable to use adhesive systems that use polymerization reactions that are strictly linked to self curing approaches.

The results of this study led to the following conclusions: 1) the best results regarding the uniformity of the hybrid layer, absence of gaps, and presence of resin tags were obtained when using self cure adhesives and resin cement systems; 2) dual cure adhesive in combination with dual cure resin cement showed fair results for the analyzed variables; 3 ) light cure adhesive 
system in combination with dual cement showed the worst results; 4) the apical third was the most critical region for all combinations of adhesives and cements analyzed in this work.

\section{RESUMO}

Este estudo in vitro avaliou as interfaces adesivas de pinos intraradiculares de fibra de vidro e a dentina radicular utilizando microscópio eletrônico de varredura (MEV). Quarenta e oito pré-molares unirradiculares foram divididos ao acaso em seis grupos, compostos por sistemas adesivos de cura química, dual ou fotopolimerizável, associado com cimentos resinosos de polimerização química ou dual. As análises microscópicas mostraram a maior continuidade, densidade e morfologia da camada híbrida e prolongamentos resinosos para a associação entre adesivos e cimentos auto-polimerizáveis seguido pelo grupo do adesivo de dupla polimerização e cimento de resina auto-polimerizável, e finalmente pelo adesivo fotopolimerizável e cimento de resina auto-polimerizável. Para os cimentos resinosos de dupla polimerização a mesma relação pode ser observada. O terço apical mostrou ser o substrato mais crítico em relação aos critérios avaliados para todas as associações entre os materiais usados(testes de Kruskal-Wallis e Friedman $p<0,001$ ). De maneira geral, a simplificação dos passos do sistema adesivo e a reação de polimerização dos adesivos e cimentos resinosos produzem efeitos diretos na qualidade da interface adesivo pino/dentina.

\section{ACKNOWLEDGEMENTS}

The authors wish to thank FAPEMIG, CAPES, FINEP, CNPQ and the Graduate Program of the Dental School of the Federal University of Minas Gerais, Brazil.

\section{REFERENCES}

1. Duret PB, Reynaud M, Duret F. Un noveau concept de reconstituction corono-radiculaire: le composipost. Le Chi Dent de France 1990;60:131-141.

2. Asmussen E, Peutzfeldt A, Heitmann T. Stiffness, elastic limit, and strength of newer types of endodontics posts. J Dent 1999;27:275278.

3. Ferrari M, Mannocci F, Vichi A, Cagidiaco MC, Mjor IA. Bonding to root canal: structural characteristics of the substrate. Am J Dent 2000;13:255-260.

4. Ferrari M, Vichi A, Grandini S. Efficacy of different adhesive techniques on bonding to root canal walls: an SEM investigation. Dent Mater 2001;17:422-429.

5. Faria-e-Silva AL, Pedrosa-Filho CF, Menezes MS, Silveira DM, Martins LRM. Effect of reling on fiber post retention to root canal. J Appl Oral Sci 2009;17:600-604.

6. Silva RAT, Coutinho M, Cardozo PI, Silva LA, Zorzatto JR Conventional dual-cure versus self-adhesive resin cements in dentin Bond integrity. J Appl Oral Sci 2011;19:355-362.

7. Silva GR, Santos-Filho, Simamoto-Júnior PC, Martins LRM, Mota
AS, Soares CJ. Effect of post type and restorative techniques on the strain and fracture resistance of flared incisor roots. Braz Dent J 2011;22:230-237.

8. Mallmann A, Jacques LB, Valandro LF, Muench A. Microtensile bond strength of photoactivated and autopolymerized adhesive systems to root dentin using translucent and opaque fiberreinforced composite posts. J Prosthet Dent 2007;97:165-172.

9. Chersoni S, Acquaviva GL, Prati C, Ferrari M, Gardini S, Pashley $\mathrm{DH}$, et al.. In vivo fluid movement though dentin adhesives in endodontically treated teeth. J Dent Res 2005;84:223-227.

10. Pedreira APRV, Pegoraro LF, Góes MF, Pegoraro TA, Carvalho RM. Microhardness of resin cements in the intraradicular environment: effects of water storage and softening treatment. Dent Mater 2009;25:868-876.

11. Teixeira CS, Silva-Sousa YTC, Sousa-Neto MD. Bond strength of fiber posts to weakened roots after resin restoration with different light-curing times. J Endod 2009;35:1034-1039.

12. Ceballos L, Garridob MA, Fuentesa V, Rodríguez J. Mechanical characterization of resin cements used for luting fiber posts by nanoindentation. Dent Mater 2007;23:100-105.

13. Grandini S, Sapio S, Goracci C, Monticelli F, Ferrari M. A one step procedure for luting glass fibre posts: an SEM evaluation. Int End J 2004;37:679-686.

14. Guiselin N, Courcot L, Artigas LP, Jéloux AL, Brylinski JM. An optimised protocol to prepare Phaeocystis globosa morphotypes for scanning electron microscopy observation. J Microbiol Methods 2009;77:119-123.

15. Morgan LFSA, Albuquerque RC, Poletto LTA, Peixoto RTRC, Corrêa MFS, Pinotti MB. Light transmission through translucent fiber posts. J Endod 2008;34:299-302.

16. Faria-e-Silva AL, Arias VG, Soares LE, Martin AA, Martins LR. Influence of fiber-post translucency on the degree of conversion of a dual-cured resin cement. J Endod 2007;33:303-305.

17. Kanehira M, Finger WJ, Hoffmann M, Endo T, Komatsu M. Relationship between degree of polymerization and enamel bonding strength with self-etching adhesives. J Adhes Dent 2006;8:211-216.

18. Giachetti L, Grandini S, Calamai P, Fantini G, Russo DS. Translucent fiber post cementation using light- and dual-curing adhesive techniques and a self-adhesive material: push-out test. J Dent 2009;37:638-642.

19. Ferrari M, Vichi A, Grandini S. Efficacy of different adhesive techniques on bonding to root canal walls: an SEM investigation. Dent Mater 2001;17:422-429.

20. Vichi A, Grandini S, Ferrari M. Comparison between two clinical procedures for bonding fiber post into a root canal: a microscopic investigation. J Endod 2002;28:355-360.

21. Bouillaguet S, Troesch S, Wataha JC, Krejci I, Meyer JM, Pashley DH. Microtensile bond strength between adhesive cements and root canal dentin. Dent Mater 2003;19:199-205.

22. Franco EB, Lopes LG, D’Alpino PH, Pereira JC. Influence of ph of different adhesive system on the polymerization of a chemically cured composite resin. Braz Dent J 2005;16:107-111.

23. Sanares AM, Itthagarun A, King NM, Tay FR, Pashley DH. Adverse surface interactions between one-bottle light cured adhesive and chemical-cured composites. Dent Mater 2001;17:542-556.

Received January 11, 2011

Accepted September 6, 2011 